\title{
LA EVOLUCIÓN SOCIO-CULTURAL DE LA AMAZONÍA PREHISPÁNICA Y COLONIAL: NUEVAS PERSPECTIVAS EN LA INVESTIGACIÓN ARQUEOLÓGICA Y ETNOHISTÓRICA
}

\author{
Juan Carlos Solórzano Fonseca*
}

\begin{abstract}
Resumen: Durante años se pensó que la Amazonía había estado escasamente poblada en el período prehistórico y apenas ocupada por pequeñas sociedades cazadoras recolectoras. El siguiente trabajo resume y analiza los hallazgos de investigaciones recientes que muestran que, por el contrario, esta región estuvo entonces densamente habitada, y llegó a albergar incluso sociedades de compleja organización económica y social. Con el arribo de los europeos, este modo de vida comenzaría a desestructurarse hasta desaparecer, al tiempo que ocurría un acentuado declive demográfico.
\end{abstract}

Palabras clave: arqueología, etnohistoria, agricultura, demografía, historiografía, período prehispánico, período colonial, Amazonía.

\begin{abstract}
The Amazonia was longtime believed a barely inhabited region, with scattered hunter-gatherers tribes living there. This article, based on new research and findings, shows how, on the contrary, this territory had been densely populated. Socially complex villages occupied it throughout its pre-history times. It also exposes how the arrival of European was the start of the uprooting of local tribal organization and a severe population decline.
\end{abstract}

Fecha de recepción: 10/02/2017 - Fecha de aceptación: 16/04/2017

* Costarricense. Doctor en Historia por la École des Hautes Études en Sciencies Sociales (EHESS), Paris I Panthéon Sorbonne, Francia. Catedrático, profesor e investigador jubilado de la Escuela de Historia de la Universidad de Costa Rica (UCR) y del Posgrado en Historia de esa misma universidad. Es académico de número de la Academia de Geografía e Historia de Costa Rica y correspondiente en la Academia de Historia y Geografía de Guatemala. Correo electrónico: jcsolorzanof@gmail.com 
Keywords: archaeology, ethno history, agriculture, demography, historiography, pre-Hispanic period, colonial period, Amazonia.

\section{Introducción}

En 1492, a la llegada de los españoles al continente americano, este era un inmenso mosaico de culturas y pueblos con niveles de desarrollo muy desigual. Las sociedades de carácter estatal en las regiones nucleares de Mesoamérica y los Andes Centrales coexistían con cacicazgos poderosos o "señoríos" en territorios como Centroamérica, Colombia, Ecuador -el Área Intermedia- y en otras regiones. También existían gran cantidad de poblaciones de cazadores-recolectores organizados en tribus o en cacicazgos muy pequeños y menos complejos en su organización social. Se dio por sentado que esta forma de agrupación constituía el tipo de sociedad predominante en la Amazonía desde que la antropóloga estadounidense Betty Meggers compartió su trascendental estudio Man and Culture in a Counterfeit Paradise, publicado en 1971 y en el que argumentó que la lujuriante vegetación de la Amazonía habría impuesto importantes limitaciones para la obtención de recursos por parte de los humanos, lo que impidió el crecimiento de la población, así como su evolución hacia una mayor complejidad social que la de tribus o diminutos cacicazgos. ${ }^{1}$

Se asumió, entonces, que en la región amazónica habrían predominado sociedades de cazadores y recolectores con una agricultura básica y marginal de slash and burn, o de roza y quema de la vegetación, que obligaba a la mudanza continua de los asentamientos. Por ello, los conglomerados humanos en la selva habrían sido siempre pequeños y dispersos: caseríos que agrupaban familias extensas aisladas - clanes familiares-, o bien agrupamientos de familias, separadas entre sí por distancias considerables y, por lo general, en aldeas rodeadas de paliçadas -empalizadas-defensivas.

Meggers planteó dos premisas básicas para sustentar su interpretación de que en tal medioambiente no se daban las condiciones básicas para el surgimiento de concentraciones de población densas y sedentarias. La primera razón es que la selva amazónica era en sí un limitante para el desarrollo y comunicación de los grupos humanos. La segunda condición adversa era la pobreza del suelo amazónico, no apto para la explotación agrícola a gran escala y que hacía imposible la práctica de una agricultura que sustentara grupos humanos grandes y estructurados, lo que constituía un limitante para el crecimiento de la población y la complejidad social.

1 Betty J. Meggers, Amazonia: Man and Culture in a Counterfeit Paradise (EE. UU., Washington D.C.: Smithsonian Institution, Revised edition 1996). 
El enfoque de Meggers vino a reforzar la idea, ya aceptada por los estudiosos de los informes de los frailes misioneros -quienes durante el siglo XVIII realizaron tareas de evangelización en la región amazónica-, de que los habitantes de la Amazonía se caracterizaban por agruparse en poblaciones pequeñas, dispersas en la selva y con estructuras sociales muy básicas. Se trataba, pues, de un modo de vida sustentado en la caza, la recolección y la pesca. Y aunque algunos grupos disponían de cultivos, no podían permanecer mucho tiempo en un solo lugar. Al agotarse los suelos debían desplazarse hacia otros sectores en los bosques donde nuevamente procedían a clarear un terreno para sus nuevas siembras.

A partir de 1991 comenzó a ser cuestionado el planteamiento de Betty Meggers. La antropóloga estadounidense Anna Curtenius Roosevelt puso en duda el modelo de poblamiento de Meggers, así como la afirmación de que el Amazonas fuese un "falso paraíso", como subtitulara Meggers su libro de 1971. Justo dos décadas después de Meggers, Roosevelt publicó Moundbuilders of the Amazon: Geophysical Archaeology on Marajó Island, Brazil, ${ }^{2}$ libro en el que desafió la teoría de Meggers de que las características de esta región no permitieran el sustento de una población densa y organizaciones socio-políticas complejas. Al contrario, para Roosevelt las sociedades que surgieron en el Amazonas lograron "uno de los más sobresalientes logros culturales, con alta concentración de población, agricultura intensiva de subsistencia, así como construcciones públicas de gran envergadura". ${ }^{3}$

A raíz de esta última publicación, se desató un intenso debate en torno al tema de la antropología y la arqueología de la región de Marajó. A su vez, otros investigadores inspirados en las ideas de Roosevelt, realizaron sus propias excavaciones en diversas localidades de la Amazonía, llegando a conclusiones similares a los planteamientos de Roosevelt, lo que puso en evidencia los equívocos de Meggers, quien publicó su investigación en 1971, cuando ciertamente no se disponía de las técnicas de investigación propias de la arqueología actual. ${ }^{4}$

2 Anna Curtenius Roosevelt, Monundbilders of the Amazon: Geophhysical Archaeloloy on Marajo Island, Brazil (San Diego, EE. UU.: Academic Press, 1991).

3 Citado por Charles C. Mann, 1491: New Revelations of the Americas Before Columbus (New York, EE. UU.: Vintage Books, 2006), 335.

4 El debate se mantiene: Meggers ha criticado a sus oponentes y éstos han respondido. Vid. Michael J. Heckenberger, James B. Petersen, y Eduardo Góes Neves, "Of Lost Civilizations and Primitive Tribes, Amazonia: reply to Meggers", Latin American Antiquity (EE. UU.) 12, n. 3 (septiembre 2001): 328-333, DOI: http://dx.doi.org/10.2307/971637, URL: http://www. jstor.org/stable/971637. 


\section{El área arqueológica del Amazonas y su evolución histórica}

El área cultural de Amazonía o Gran Amazonía incluye las regiones correspondientes a la cuenca del Amazonas, el Escudo Guayanés y los Llanos Orientales.

La cuenca fluvial del Amazonas se compone de más de mil ríos cuyas nacientes se originan en el Escudo Guayanés al norte, el Planalto Central -Escudo Brasileño- al sur y la cordillera de los Andes al oeste. El sistema reúne el $20 \%$ del agua dulce superficial del planeta y alberga el $30 \%$ de la biodiversidad del mundo.

El Escudo Guayanés presenta un bosque húmedo tropical incluso en las tierras altas que superan los 3.000 metros sobre el nivel del mar. Los Llanos Orientales cubren unos $5.00 .000 \mathrm{~km}^{2}$ de sabana inundable con dos estaciones marcadas - lluvia y sequía- y suelos con pobre drenaje, condiciones adversas que las poblaciones prehispánicas resolvieron con la construcción de campos elevados y canales para controlar los niveles de agua.

Los sistemas fluviales, cruciales para los grupos indígenas como medio de subsistencia, fueron las rutas de intercomunicación de toda el área. Se trata de regiones con sus características propias. En ellas abundan recursos para la subsistencia humana: grandes planicies inundables, extensas costas y estuarios y tierras elevadas calizas o volcánicas.

El Proyecto Central Amazónico, desde la década de 1960, ha estudiado las culturas precolombinas que existieron en la región central amazónica. Con la información obtenida se elaboró una secuencia del desarrollo humano en la Amazonía que muestra cuán prolongado y complejo fue este proceso, mucho más de lo que previamente se había creído. Se detectó una ocupación humana desde el Pleistoceno tardío con cazadores-recolectores que desarrollaron una tecnología lítica y arte parietal. Todo indica que surgió aquí uno de los más tempranos asentamientos sedentarios del Nuevo Mundo con cerámica y horticultura, así como -durante la Prehistoria tardía- populosas sociedades indígenas que alcanzaron una escala y complejidad notables. ${ }^{5}$

Las fases fundamentales que caracterizaron la evolución socio-económica de los pueblos de la región amazónica antes del arribo de los europeos son:

Una de cazadores-recolectores, cuya más antigua presencia se encuentra en la Caverna da Pedra Pintada, un abrigo rocoso en el bajo Amazonas donde huellas humanas han sido datadas correspondientes al 9.200 a.C.

5 Vid. Anna Curtenius Roosevelt (ed.), Amazonian Indians: from Prehistory to the Present: Anthropological Perspectives (Tucson, Arizona, EE. UU.: The University Arizona Press, 1994) y Anna Curtenius Roosevelt, "The Rise and Fall of the Amazon Chiefdoms", L'Homme (Francia) 33, n. 126-128 (1993): 255-283, DOI: http://dx.doi.org/10.3406/hom.1993.369640, URL: www.persee.fr/doc/hom_0439-4216_1993_num_33_126_369640. 
Estos pueblos elaboraron algunas de las puntas de proyectil más grandes y finamente elaboradas de la América Prehispánica. También realizaron numerosas y refinadas pinturas polícromas rupestres. Sus actividades económicas de subsistencia comprendían, desde la cacería especializada de grandes animales acuáticos y terrestres hasta la recolección intensiva de pequeñas especies de animales y plantas. Gracias a las similitudes estilísticas encontradas en los artefactos de áreas distantes entre sí, se ha determinado que existía un intercambio de larga distancia de personas, comercio y comunicación de ideas y tecnología.

Tres milenios más tarde, hacia el 6.000 a.C., aparecen las primeras comunidades sedentarias a orillas de algunos ríos y en la costa: grandes acumulaciones de conchas, restos de peces y otros animales aparecen al lado de fragmentos de cerámica, considerados los más antiguos del continente americano, correspondientes al 5.000 a.C.

A comienzos del primer milenio antes de Cristo, surgieron en la Gran Amazonía grupos humanos que se sustentaban en la horticultura. Con ellos aparece el más temprano conjunto de cerámica decorada que se conoce en Suramérica, resultado de una posible expansión de aldeas horticultoras en las tierras bajas inundables del Amazonas.

Estas poblaciones combinaban el cultivo de raíces, con la caza y la pesca: eran grandes consumidores de peces, mamíferos acuáticos, tortugas y otros mamíferos terrestres, así como de aves.

Nuevos asentamientos ubicados en las orillas de los ríos y lagos se expandieron en territorios antes no colonizados. El análisis de sus depósitos de deshechos indica que sus prácticas productivas incluyeron cultivos. Se deduce que, hacia esos años, en asentamientos de modestas proporciones y dispersos, inició una sedentarización de los pueblos amazónicos basada en una combinación del cultivo de yuca con la caza y la pesca, donde la proteína de origen animal fue la base de su sustento. ${ }^{6}$

Estas sociedades emplearon la cerámica; pero no habían desarrollado lo que será esencial en muchas de ellas a partir de la segunda mitad del milenio previo al inicio de nuestra era: la llamada terra preta, suelos fértiles de color negro, sumamente productivos para la agricultura, producidos por los humanos mediante la acumulación de restos orgánicos e inorgánicos. La más antigua fecha obtenida por medio de radiocarbono de terra preta corresponde al 450 a.C. ${ }^{7}$

6 Curtenius Roosevelt, “The Rise and Fall...”, 258.

7 Michael J. Eden, Warwick Bray, Leonor Herrera y Colin McEwan, "Terra Preta soils and their Archaeological Context in the Caqueta Basin of Southeast Colombia", America Antiquity (EE. UU.) 49, n. 1 (enero 1984): 125-140 [126], DOI: http://dx.doi.org/10.2307/280517. 
Con el surgimiento de la Terra Preta, se inició el más fructífero período de los pueblos amazónicos en el que alcanzó gran desarrollo la agricultura, la horticultura y el manejo apropiado de la selva. Concomitantemente, se produjo un notable incremento de la población, así como formas de vida sedentaria permanentes y el florecimiento de distintas tradiciones culturales. ${ }^{8}$

El más detallado mapeo de depósitos de Terra Preta en un solo lugar se ubica en las riberas del río Arapiuns, ${ }^{9}$ el cual revela muchos centenares de sitios separados. Algunos son muy extensos. Así, por ejemplo, Manacapurú, en el Amazonas medio, cerca del pueblo de Alenquer, se extiende por más de dos kilómetros de longitud por 400 metros de ancho. Y aunque previamente se consideraba que solo se localizaban en las planicies inundables, se les ha encontrado también en tierras altas interfluviales, aunque son depósitos por lo general de menores extensiones que los de las tierras bajas. ${ }^{10}$

El número y distribución de los depósitos de Terra Preta sugiere que en el Amazonas pocas partes o quizás ninguna estuvieron sin poblar durante la Prehistoria, y que tanto las tierras bajas inundables como las tierras altas -tierra firme- fueron colonizadas y conocieron los mismos procesos de producción agrícola intensiva y de concentración demográfica.

Se han localizado depósitos de Terra Preta en lugares donde predominan las tierras arenosas y aguas negras, consideradas problemáticas para la agricultura. Así, en las orillas del río Arapiuns se encuentran cientos de depósitos de Terra Preta reconocidos aún y explotados por los agricultores actuales. Aún más, parece que, habiendo sido abandonados por largo tiempo, la dinámica de esta Terra Preta es tal que se expande en el transcurso del tiempo, al punto que algunos investigadores consideran que se comporta más como un organismo viviente que como un fósil. ${ }^{11}$

A partir de mediados del primer milenio de nuestra era, los pobladores del Amazonas introducen también otros sistemas de producción agrícola, tales

8 David Clearly, "Towards an Environmental History of the Amazon. From Prehistory to the Nineteenth Century", Latin American Review (EE. UU.) 36, n. 2 (2001): 65-96, URL: http:// www.jstor.org/stable/2692088.

9 Es un tributario del río Tapajó, el cual se une a este cerca de 30 kilómetros antes de que el Tapajó desagüe en el río Amazonas.

10 Eden, Bray, Herrera y McEwan “Terra Preta soils...”, 125.

11 David Clearly, 77. 
como camellones de cultivo, ${ }^{12}$ con los que se controla la humedad. De esos años datan también redes de caminos, montículos funerarios, así como las aldeas rodeadas de pozos y empalizadas, todo lo cual es evidencia de que existía ya una gran complejidad social al interior de los pueblos.

En los mil años que transcurren entre la introducción de los nuevos sistemas de producción agrícola y el arribo de los europeos a mediados del siglo XVI, proliferaron los asentamientos en toda la región amazónica; surgieron horizontes culturales suprarregionales en las tierras bajas, cuyos estilos cerámicos se caracterizan por su elaborada imaginería geométrica-zoomórfica de tipo incisivo, mientras que en ciertas áreas se empleó el pintado rojo, o rojo con blanco. Las representaciones artísticas más reconocibles son los animales, algunas veces con diseño antropomórfico. Esta iconografía se asocia actualmente con una cosmogonía alusiva a la importancia de la abundancia animal y a la fertilidad humana.

El cultivo de raíces se modificó para dar lugar a prácticas agrícolas que integraban de manera creciente el cultivo de semillas. Esta agricultura requería de un trabajo intensivo de labor agrícola a lo largo de todo el año, por lo que surgió un nuevo sistema de organización socio-política conocida como cacicazgo, capaz de orientar y distribuir la mano de obra en las nuevas tareas de cultivo.

La economía de estas sociedades era más compleja y de mayor escala, pues incluía la producción intensiva de alimentos, cosecha de semillas y raíces, tanto en campos de monocultivo como de policultura. También incluía la caza y la pesca intensivas, así como el almacenamiento a largo plazo. Un considerable número de trabajos era llevado a cabo en la edificación de instalaciones permanentes como corrales para tortugas, estanques para piscicultura, así como cultivos permanentes. Se ha determinado la existencia de campos de cultivo en una escala impresionante: alrededor de 50.000 acres en Llanos de Mojos y 15,5 kilómetros cuadrados en Caño Ventosidad en Venezuela, que en teoría podrían haber sustentado a cientos de miles de habitantes. ${ }^{13}$

12 Los camellones constituyen un tipo de disposición del suelo en la llanura para el cultivo, que se usó extensamente en tiempos precolombinos en zonas inundables de lo que hoy es Colombia, Ecuador, Perú y Bolivia. Se cavaban canales conectados, usando la tierra obtenida para formar camas de cultivo elevadas. El agua sube de los canales a las camas por capilaridad, provocando que las raíces de las planta se orienten hacia abajo, lo que permite colocar las plantas muy próximas unas de otras. En los valles fluviales de las zonas bajas los canales eran navegables; proveían pesca y recolección de mariscos, en tanto las partes altas se empleaban también para colocar las casas.

13 David Clearly, 75. 
El sistema agrícola desarrollado por estos pueblos se conoce como slash and char -roza y carbonización- en oposición al más conocido de slash and burn -roza y quema-. Este último convierte en cenizas la selva rozada al ser quemadas las plantas segadas con el fin de utilizar para la siembra el espacio así clareado. En cambio, en el sistema de roza y carbonización, las malezas y árboles cortados solo se chamuscan con el objetivo de convertirlos en carbón vegetal -biocarbón-. Este carbón era utilizado por las poblaciones del Amazonas para la fabricación de la Terra Preta. Lo enterraban en el suelo o bien formaban montículos, con el fin de convertir en productivos los suelos exhaustos por el uso intensivo tras sembrar cosecha tras cosecha. Es precisamente esta tierra la que se encuentra en gran cantidad de sitios en el Amazonas y en otras partes de Suramérica: grandes extensiones aún aprovechables de tierra negra fértil después de cientos de años de su fabricación. Gracias a este sistema de cultivo inventado por los pueblos amazónicos, se lograron grandes cosechas de maíz, año tras año, en los siglos previos al arribo de los europeos. ${ }^{14} \mathrm{Y}$ esta fue la base que permitió el crecimiento de la población y el surgimiento de complejos sistemas de organización social: grandes cacicazgos.

La economía de estas sociedades era más compleja y de mayor escala, ya que incluía la producción intensiva de alimentos, cosecha de semillas y raíces, tanto en campos de monocultivo como de policultura. También se practicaba la caza y la pesca intensivas, así como el almacenamiento a largo plazo. Un considerable número de trabajos tenía por objetivo la edificación de instalaciones permanentes como corrales para tortugas, estanques para piscicultura y campos permanentes para cultivos. La proteína proveniente de la fauna silvestre continuó ocupando un papel suplementario en la dieta, proporcionando la fauna acuática más recursos que la terrestre, especialmente en las tierras bajas inundables, debido a la mayor biomasa y el volumen mayor de pesca en este ambiente, comparado con la caza de animales terrestres. ${ }^{15}$

Los cacicazgos expandieron sus dominios sobre amplios territorios, algunos de los cuales alcanzaban hasta decenas de miles de kilómetros cuadrados en extensión, unificados bajo el poder de jefes supremos. ${ }^{16}$ La población se hallaba densamente concentrada, con algunos centros que reunían a muchos miles de habitantes. Se han encontrado vestigios de grandes construcciones

14 El biocarbono se lograba obtener por medio de la incompleta combustión a baja temperatura de los arbustos y árboles cortados para limpiar los terrenos preparados para la siembra. Vid. Li-qin Niu, et al., "Slash-and-char: An Ancient Agricultural Technique Holds New Promise for Management of Soils Contaminated by $\mathrm{Cd}, \mathrm{Pb}$ and $\mathrm{Zn}$ ”, Environmental Pollution, 205 (octubre 2015): 333-339, DOI: http://dx.doi.org/10.1016/j.envpol.2015.06.017.

15 Curtenius Roosevelt, “The Rise and Fall...”, 267.

16 Ibid, 259. 
como montículos y otras obras para la conducción y almacenamiento de las aguas usadas para el trabajo agrícola, hechas mediante la remoción de tierra. También se edificaron complejos habitacionales y obras de transporte y defensa.

Se ha podido determinar que algunos de los asentamientos medían muchos kilómetros cuadrados de extensión con una alta densidad poblacional. Prueba de ello son los depósitos de restos culturales y biológicos que alcanzan varios metros de profundidad. Muchos de los restos de estos asentamientos son montículos compuestos de capas de edificaciones derruidas superpuestas entre sí, sobre las que se volvió a construir.

Los asentamientos contaban con varios miles o decenas de miles de habitantes agrupados en grandes entidades políticas y culturales bajo el poder de jefes supremos que proclamaban su origen divino, quienes hacían gala de su estatus al ser cargados en literas profusamente adornadas.

Aunque el número de asentamientos pequeños y simples es mucho más numeroso, los de mayor tamaño muestran una gran complejidad. En ellos se aprecian áreas determinadas para actividades específicas tales como joyería, fabricación de herramientas de piedra o destinadas a la celebración de ceremonias; sitios usados como cementerios, zonas de aglomeración de unidades domésticas, etc. También construcciones defensivas: empalizadas y fosos.

Las sociedades cacicales se tornaron expansionistas y guerreras con organizaciones sociales jerárquicas, sustentadas en el cobro de tributo y una economía basada en la producción de cosechas y el forrajeo intensivo. Las artesanías alcanzaron un alto desarrollo asociadas a las actividades ceremoniales y al comercio, con una diversidad de objetos cuya estilística representaba figuras humanas, diseños que vinieron a sumarse a los ya existentes de figuras de animales y geométricas. También tuvo lugar la proliferación del culto a ídolos e imágenes asociados a los ancestros de los jefes supremos.

Artículos de cerámica decorada, tejidos, herramientas diversas, alimentos y materias primas eran intercambiados a gran distancia. Para tal propósito existían sitios que funcionaban como mercados en los que cuantiosos intercambios se llevaban a cabo de manera periódica. Cuentas de collares, usualmente de concha eran utilizadas como medio de pago, en tanto que ornamentos de piedras semipreciosas como las piedras verdes, formaban parte del sistema de intercambio de regalos entre las élites.

En los lugares donde residían los jefes o en los sitios de peregrinaje se llevaban a cabo ceremonias religiosas comunales en las que se suministraba a los presentes chicha de maíz, recolectado por medio de tributo. Las ceremonias eran acompañadas con música y bailes. Se ha determinado que en el bajo Amazonas las diversas entidades políticas disponían de ideologías religiosas que resaltaban el estatus de las élites por medio de rituales de ancestros deificados en cuyo nombre se exigía el tributo. Tanto las momias como las 
imágenes pintadas de los ancestros de los jefes junto con imágenes en piedra de deidades y objetos de culto eran conservadas en edificaciones especiales, las cuales eran remozadas durante la realización de las periódicas ceremonias. Había individuos cuya única función era encargarse de las construcciones religiosas y ceremoniales, así como otros eran adivinos y curanderos. Según la documentación la genealogía de los jefes era matrilineal e igualmente se practicaba la endogamia en la élite del poder.

Las sociedades constructoras de grandes montículos se desarrollaron en las siguientes áreas de la Gran Amazonía: la cultura de Llanos de Mojos y la de Chiquitos en la Amazonía boliviana; las tierras altas de la Amazonía ecuatoriana; la isla de Marajó en la desembocadura del Amazonas; las planicies costeras de las Guayanas y el Orinoco medio. Muchos de los trabajos hechos usando como materia prima la tierra incluyen campos elevados, canales, diques, pozos, lagunas artificiales, calzadas, así como montículos con casas en lo alto o para enterramientos. Estos montículos fueron construidos apilando gruesas capas de tierra extraídas de pozos o bien por la gradual acumulación de deshechos y ruinas de edificaciones con adobes. Algunas de las zonas en donde se localizan estas sociedades constructoras de montículos se caracterizan por la existencia de inundaciones periódicas, por lo que los lugares habitados debían encontrarse en terrenos a salvo del agua. Sin embargo, como muchos de los montículos se ubicaban a varios metros por encima del máximo nivel alcanzado por las aguas, se piensa que eran construidos principalmente para defensa o como demostración de poder.

La escala y extensión de los trabajos en tierra de la Amazonía es, en definitiva, extraordinaria, así como la dimensión de los sitios. Muchos de los montículos se elevan por encima de los 3 metros alcanzando a veces los 10 metros con extensiones de varias hectáreas. En la isla de Marajó algunos complejos con múltiples montículos se extienden en áreas de más de 10 kilómetros cuadrados con 20 o hasta 40 montículos individuales. Uno de estos sitios en las tierras altas de la Amazonía ecuatoriana mide 12 kilómetros cuadrados de área.

Las áreas arqueológicas que se formaron por la acumulación de deshechos de los habitantes prehistóricos constituyen una proporción considerable de la superficie terrestre a lo largo de las riberas de los ríos Amazonas y Orinoco. Estos depósitos arqueológicos que datan de los tiempos prehistóricos tardíos son masivos, en ocasiones se extienden continuamente por decenas de kilómetros y se encuentran densamente abarrotados de artefactos y restos de plantas carbonizadas. ${ }^{17} \mathrm{Al}$ analizar estas zonas, la investigadora Roosevelt señala que, puesto que albergaban poblaciones de varios miles de habitantes e incluso algunos hasta de decenas de miles, tal escala y complejidad

$17 \mathrm{Ibid}, 272-273$. 
es indicación de que dichos asentamientos eran el territorio de sociedades con un nivel socio-político que podrían ser considerados como Estados. ${ }^{18}$

Esto explica por qué, cuando los europeos iniciaron su expansión y navegación por el Amazonas hacia 1550, encontraron sociedades con una alta densidad de población, marcadas jerarquías sociales y economías basadas en la pesca, la caza y el cultivo intensivo de maíz y yuca.

El relato de Gaspar de Carvajal, capellán de los expedicionarios a las órdenes de Francisco de Orellana, sobre su primer recorrido por el río Amazonas entre 1541 y 1542, así como el de Francisco Vázquez, autor de la crónica de la expedición iniciada por Pedro de Ursúa, dan una clara imagen de lo densamente pobladas que se encontraban las márgenes del río Amazonas y las planicies ribereñas de los principales ríos de la Amazonía en los años de contacto inicial con los europeos. ${ }^{19}$ Estos dos relatos se complementan con los escritos de los exploradores ingleses, holandeses e irlandeses de esos mismos años, quienes, en su intento de establecer asentamientos en el bajo Amazonas, elaboraron informes en los que también se evidencia lo poblados que eran estos territorios.

El paisaje de la región descrito por estos primeros relatos de europeos aparece como explotado intensivamente, con grandes depósitos de yuca y otros productos almacenados en los pueblos, anchas carreteras que comunicaban a las poblaciones con los campos de cultivo, grandes encierros de tortugas en rediles, pesquerías, asentamientos defendidos por empalizadas y murallas de tierra alineados en los riscos ribereños que se extendían de manera continua por kilómetros y kilómetros, así como indican cientos de canoas desplazándose en las corrientes de agua fluvial. ${ }^{20}$

La evidencia arqueológica ha venido a corroborar el grado de veracidad de los escritos del siglo XVI: el tamaño y la apariencia de los asentamientos, los productos intercambiados, los depósitos de alimentos, así como la existencia de agricultura y el manejo de los recursos constituyen pruebas irrefutables de que los primeros relatos de europeos sobre estas poblaciones eran fidedignos.

$18 \mathrm{Ibid}, 274$. La sociedad estatal se organiza por medio de un gobierno formal y especializado, a menudo con burocracia u otra forma de grupos dirigentes. La sociedad se divide en estratos con desigual acceso a bienes, así como existe una división social del trabajo: diversos grupos realizan distintas actividades. Su base económica es la agricultura intensiva ya que solo este método de producción garantiza el suficiente alimento para sustentar la gran población que vive en estas sociedades de nivel estatal.

19 Gaspar de Carvajal, Relación del nuevo descubrimiento del famoso Río Grande de las Amazonas, (ed.) Jorge Hernández Millares (México, D.F.: Fondo de Cultura Económica, 1955) y Francisco Vázquez, El Dorado: Crónica de la expedición de Pedro de Ursua y Lope de Aguirre, (ed.) Javier Ortiz de la Tabla (Madrid, Alianza, 1987).

20 David Clearly, 81. 


\section{El impacto de la colonización europea}

La conquista europea debilitó el poder político de los cacicazgos y diezmó físicamente una gran parte de la población local. Dio inicio así una de las mayores transformaciones sociales y del ecosistema en la historia de la Amazonía. Las epidemias, la desestructuración de antiguos circuitos de intercambio, los misioneros que buscaban relocalizar a los indígenas sobrevivientes del primer impacto causado por la irrupción de los europeos fueron factores que desarraigaron a los indígenas de sus antiguos entornos. Empobrecidos culturalmente tuvieron que dispersarse o integrarse a nuevos ámbitos culturales creados por los europeos. ${ }^{21}$ Los grupos que hoy sobreviven en la región amazónica no pueden ser realmente considerados como descendientes de los antiguos pobladores del período pre-europeo. Son el remanente poblacional de los que fueran otrora habitantes de complejos cacicazgos del período previo a la incursión europea: poblaciones ya diezmadas, desplazadas, empobrecidas a nivel cultural y organizados en forma más simples.

Contrariamente a la idea generalizada de que fue el hostil ambiente natural lo que retardó la penetración de los colonizadores europeos en la región del Amazonas, fueron factores de otra índole los que influyeron en que la región amazónica se convirtiera en un territorio periférico para los españoles y portugueses. Principalmente su marginalización resultó más del hecho de que las metrópolis coloniales tenían limitados recursos y otras prioridades de colonización durante los siglos XVI e inicios del XVII.

Debido a la posición marginal de la región del Amazonas, tanto en el caso de la Corona española como en la portuguesa, estos imperios establecieron una alianza de conveniencia con las órdenes misionales, particularmente las de los jesuitas, franciscanos, carmelitas y mercedarios. Estos grupos religiosos se convirtieron en los principales agentes europeos en la expansión hacia las tierras bajas durante los siglos XVII y XVIII. A ellos se debe la existencia de una extensa documentación. El otro grupo que ingresó en estas tierras fue un reducido número de colonos europeos atraídos por la región o bien deportados en esas lejanas tierras. Estos civiles competían con los misioneros religiosos por el acceso a la mano de obra indígena en una economía extractiva sustentada en el trabajo forzado de los indígenas. Los esfuerzos de ambos agentes externos transformaron tanto en el largo como en el corto plazo el paisaje del Amazonas. ${ }^{22}$

21 Vid. Erick Langer y Robert H. Jackson (eds.), The New Latin American Mission History (Lincoln, Nebraska, EE. UU.: University of Nebraska Press, 1995).

22 Vid. John Hemming, Red Gold: The Conquest of Brazilian Indian (Chatham, Pitsburhg, EE. UU.: Papermac, 1995). 
Ciertamente ya habían ocurrido algunos cambios antes del establecimiento de asentamientos europeos durante el siglo XVII. Hacia 1616, cuando fue fundada la ciudad de Belem, aunque los españoles solo habían realizado expediciones esporádicas, la economía y sociedad de los amerindios del Amazonas ya había empezado a ser transformada. Desde esos años, ingleses y franceses habían establecido un número de puestos de comercio y "factorías" en el estuario y en partes bajas del Amazonas -en realidad simples rancherías rodeadas de empalizadas-, en peligro constante de ser atacadas por rivales europeos o enemigos indígenas.

Los españoles ocuparon el estuario del Orinoco desde comienzos del siglo XVI y los holandeses trataron de dominar el comercio interior del norte del Amazonas desde Surinam, luego de que fueron expulsados del estuario amazónico en el siglo XVII. ${ }^{23}$

Desde estos pequeños enclaves europeos dio comienzo la circulación de hachas de metal, cuchillos, armas y anzuelos a lo largo de rutas de comercio establecidas desde tiempo atrás por las poblaciones prehispánicas. Simultáneamente nuevas alianzas tribales y antagonismos surgieron debido al comercio de esclavos y a la disponibilidad de un nuevo orden de bienes de comercio.

Las redes de comercio fueron pronto traslapadas por las nuevas redes de distribución de las misiones durante los siguientes 150 años. Los bienes de metal eran adquiridos a cambio de alimentos, personas esclavas y las drogas do sertão. La lista de productos intercambiados da testimonio de lo versados que estaban los indígenas en el manejo de los recursos naturales, así como de la avidez de los mercados europeos: zarzaparrilla, sasafrás, vainilla -encontrada por los europeos por vez primera en el Amazonas-, canela silvestre, cacao, nuez moscada, clavo, carne y aceite de manatí, carne, huevos y caparazones de tortuga, plumas de todo tipo de aves, cumarín -o frijol de tonka- empleado para fabricación de perfumes, habas, maderas, corteza de quina, tabaco, hule, ceras, algodón, colapez, cáñamo, cueros, pieles, marañones, nuez de Brasil, gomas, resinas, así como una miríada de productos regionales como el guaraná, urucum, aceite de andiroba, massarabunda, jutaicica, aceite de copaíba, aceite de ucuúba, piassava, brea, estopa, tapioca, puxurí, bombonassa, fibras de tucum, cera de carnauba, ipecac, jatobá, jarina y curate. Estos primeros ciclos extractivos han sido subestimados o eclipsados por los más conocidos ciclos extractivos del siglo XIX e inicios del siglo XX, aunque sus consecuencias ambientales fueron tan drásticas como las causadas por los más recientes.

Lo primero que debe considerarse es el incremento en la productividad agrícola causado por la afluencia de instrumentos de metal, aunque es

23 Vid. H. Van Nederveen Meerkerk, Recife, the Rise of a 17th-Century Trade City From a Cultural-Historical Perspective (Netherlands: Assen, Van Gorcum publishers, 1989). 
incierto si esto produjo el aumento del despeje de la selva. Debe inferirse que un surplus de productos alimenticios de base era necesario a fin de suplir su demanda por parte de los europeos asentados en la región. Estos rápidamente fueron adoptando la yuca como principal producto alimenticio, aunque tal mercado no llegó a ser muy significativo. Otro factor que permite inferir que la producción de yuca se tornó más productiva es el hecho de que la población indígena ya había empezado a descender a partir del siglo XVI. Fue entonces la introducción de instrumentos de metal lo que permitió, a su vez, una desviación de mano de obra local de la agricultura a la extracción de productos. Por otra parte, el uso de instrumentos de metal en agricultura no produjo un incremento dramático del desmonte de la selva.

Las nuevas cosechas europeas, la ganadería, así como los animales domesticados introducidos: gallinas, cerdos, ganado vacuno, gallinas de guinea, se convirtieron en parte de las plantas y la fauna de toda aldea amazónica a lo largo de los dos siglos posteriores al arribo de los extranjeros de ultramar.

De más importancia aún fue la transformación operada en la orientación de las redes de comercio y transporte en las tierras bajas. Previamente, el laberinto de ríos había funcionado como medio de conexión entre las tierras bajas y las altas. Esta relación interna constituía el tejido esencial de toda la estructura de la sociedad y la economía local. Con el arribo de los europeos y la implantación de una economía extractiva, la economía regional fue reorientada hacia el exterior, hacia la costa. El intercambio de productos que previamente integró las comunidades de las tierras bajas del Amazonas con las tierras altas de los Andes durante miles de años se vio alterado drásticamente a medida que una nueva red de intercambio y contactos -administrativa, económica y religiosa- volcada hacia el exterior comenzó a vincular el Amazonas con Europa, aunque levemente al principio. ${ }^{24}$ De esta manera, la región amazónica pasó a ser una región aislada con respecto al resto del continente.

Las sociedades indígenas precolombinas, posteriormente diezmadas por los esclavistas, las enfermedades y el sistema de misiones, habían ocupado principalmente las tierras bajas inundables -várzea- ${ }^{-}$Irónicamente, su mismo éxito en la colonización de los ricos ambientes del sistema de ríos las puso en la ruta para la salida de esclavos, esclavas y drogas do sertão hacia la costa. En consecuencia, en un par de siglos las planicies de los ríos Solimões y Amazonas, que habían contado con las más altas densidades de población de la cuenca amazónica durante el siglo XVI, quedaron casi desiertas. Este hábitat se transformó en un paisaje vacío, ocupado por aldeas aisladas y escasas haciendas de colonos separadas entre sí por enormes distancias.

24 Vid. Jeronimo de Viveiros, História do Comércio do Maranhao (1612-1895) (Brasil: Associaçao Comercial do Maranhao, 1954). 
No solo las bajas planicies inundables fueron modificadas por la economía colonial. Las drogas do sertão procedían no solo de las tierras bajas sino también de las tierras altas, por lo que, con el gran interés en obtener cantidades comercializables de estas, la sustentabilidad del ecosistema fue poco tomada en cuenta.

Con el paso del tiempo, los esclavistas, los extractores de recursos y los misioneros fueron constreñidos a internarse cada vez más al interior, a fin de obtener más recursos, una vez que los sitios más accesibles habían sido sobreexplotados y agotados. Aunque no se conoce en detalle este "asalto extractivista colonial", lo cierto es que para el siglo XIX diversos productos ya se habían seriamente agotado. Prueba de ello es que para la década de 1840 las cifras sistemáticas de exportación sobre las que se basaban los impuestos indicaban una escasa exportación de productos derivados de tortugas y manatíes. Pero este no fue el caso durante el período colonial: son numerosas las descripciones de la explotación en gran escala de tortugas y manatíes tanto para mercados locales como externos.

Estos animales fueron muy importantes por el número de productos derivados de su captura. Las tortugas proveían carne fresca y salada, sus caparazones se empleaban en joyas y peines. También se consumían sus huevos y se extraía su grasa, productos que adquirieron importancia en las tierras bajas durante los años coloniales, cuando las poblaciones de las aldeas se trasladaban hacia los bancos de arena durante semanas enteras para la recolección de huevos y para extraer la grasa de estos animales durante determinados meses del año.

De los manatíes se obtenía su carne y manteca. La mexira constituía carne de manatí cocinada y preservada en su propia grasa y constituía un importante producto de exportación. Pasaron dos siglos antes de que la explotación de tortugas y de manatíes provocaran su casi total extinción. Fue probablemente la desviación de la mano de obra hacia la extracción del caucho, en la década de 1850, lo que impidió la total desaparición de ambas especies de animales en el Amazonas. ${ }^{25}$

Otros recursos explotados durante el período colonial sobrevivieron mejor la explotación de esos años. Así, por ejemplo, nunca se mencionó la disminución de pescado. El pescado secado y salado, especialmente el Pirarucú, un sustituto del bacalao, era consumido tanto localmente como exportado. Se considera que la poca explotación de pescado obedeció a la preferencia cultural por la carne por parte de las élites urbanas.

25 Vid. John Hemming, Tree of Rivers: The Story of the Amazon (London, Inglaterra: Thames and Hudson, 2009). 


\section{Las enfermedades}

Si la economía colonial afectó sobremanera el paisaje, otro aspecto que debe considerarse es el de la demografía. Según David Cleary, el tema es controversial: se ha considerado que la región del Amazonas experimentó el mismo devastador impacto de las epidemias que otras partes del continente americano. Sin embargo, en contraste con las densas poblaciones indígenas de los Andes y Mesoamérica, que mantuvieron un estrecho contacto con contingentes de población europea relativamente grandes y recibieron el impacto directo de las epidemias mortíferas que estas propagaron, las poblaciones amazónicas más dispersas localizadas en áreas geográficas mucho más extensas sufrieron un menor impacto. Además, la penetración europea fue mucho más esporádica en sus inicios, razón por la que los pueblos amazónicos fueron afectados por las enfermedades europeas más tardíamente que otros pueblos americanos. Aún en la actualidad este es el único lugar del continente americano donde continúa este proceso, por medio de ciclos de infección que viajan a lo largo de las rutas de comercio, con contacto físico directo, o sin este, entre indígenas y no indígenas.

La viruela no aparece mencionada en las fuentes europeas del siglo XVI, cuando se refieren a las poblaciones indígenas del Amazonas o del Orinoco, aun cuando algunos europeos ya se habían instalado allí desde comienzos de la centuria. En cambio, por esos mismos años, la viruela estaba causando estragos entre los incas, los aztecas, así como en las poblaciones nativas de las islas del Caribe. Independientemente de cuáles hayan sido las causas de que no se presentara esta enfermedad durante ese siglo, no fue sino hasta entrado el siglo XVII cuando la viruela comenzó a propagarse entre los indígenas amazónicos. Diversas explicaciones pueden adelantarse, tales como la intolerancia del virus de la viruela al calor o a la luz intensa del sol, la orientación del comercio amazónico hacia la costa, lejos de los Andes, o incluso la irregularidad del contacto directo con los europeos.

Los primeros casos documentados de viruela en el Amazonas datan de 1621, como consecuencia directa del objetivo de los portugueses de desplazar a otros europeos del estuario del río Amazonas. La enfermedad habría sido traída por un barco proveniente del noreste brasileño donde la viruela se había ya fijado desde mediados del siglo XVI.

A partir de 1621 la viruela pasó a formar parte de la realidad cotidiana de los pueblos amazónicos. A lo largo del siglo XVII se fue propagando rápidamente, aunque de manera irregular, y afectó la región hasta bien entrado el siglo XX. Fue así, aunque desde el año de 1829 un misionero carmelita intentó introducir la vacunación en el Amazonas, como se produjo una fuerte 
resistencia popular en contra de tal medida. ${ }^{26}$ Las fuentes misionales dan cuenta de los horrorosos casos, tanto en el extremo occidental de la cuenca amazónica como en los pueblos de Llanos de Mojos, en la actual Bolivia. Un siglo después, sin embargo, su mortalidad declinó debido a que los sobrevivientes desarrollaron resistencia y los brotes epidémicos se tornaron menos frecuentes.

Lo que se ha podido determinar es que hubo una gran variación en los ciclos de los brotes de la enfermedad, su mortalidad, así como en la resistencia a lo largo del tiempo y del espacio territorial, de manera que algunos grupos de población conocieron un crecimiento demográfico, en tanto que otros sucumbieron debido a sus altas tasas de mortalidad.

La secuencia de los eventos no fue determinada exclusivamente por el contacto físico con los europeos, sino por otra serie de factores: la geografía, la participación de las poblaciones en las redes de comercio y en la economía colonial, su relación de los amerindios con el sistema de misiones, etc.

En medio de este complejo panorama para las poblaciones locales, es importante subrayar que la región de las planicies bajas inundables se convirtió rápidamente en el sitio más inhospitalario para los indígenas amazónicos, no solo por el relativo fácil acceso para esclavistas y misioneros, sino porque sus características posibilitaban una rápida propagación de la malaria y otras enfermedades transmitidas por insectos.

Aunque se considera que algunas cepas de malaria pueden haber precedido el arribo de los europeos, el ambiente de las tierras bajas inundables aseguró que las nuevas cepas europeas y africanas rápidamente se tornaran endémicas. ${ }^{27}$

Otro aspecto a retener es que la enfermedad estuvo estrechamente vinculada a la geografía del sistema de misiones por la ubicación de estos poblados a la orilla de los ríos. Las misiones fueron escasamente efectivas en la propagación de la fe, pero sí muy eficientes sistemas de propagación de enfermedades. Concentraban poblaciones de diferentes etnias y de distintas localidades en un solo lugar y aseguraban el contacto físico regular con los europeos; a la vez, interrumpieron los sistemas agrícolas tradicionales y de manejo de recursos al intentar infructuosamente desarrollar un sistema de pseudo-campesinado dedicado al monocultivo de tipo europeo.

En realidad, el impacto letal de las enfermedades en los indígenas del Amazonas se produjo particularmente en el siglo XIX. Durante el período colonial, ciertamente las enfermedades contribuyeron al descenso

26 David Clearly, 87.

27 Vid. J. R. McNeill Mosquito Empires: Ecology and War in the Greater Caribbean (16201914) (Cambridge, Inglaterra: Cambridge University Press, 2010). 
demográfico, pero fue la práctica de la esclavitud, más brutal debido a la violencia y a la dislocación de las sociedades indígenas, lo que provocó un mayor impacto en esta caída. En cuanto a las misiones, estas en sí no necesariamente provocaron la muerte de sus pobladores; pero impactaron con la desestructuración de las tribus y la asimilación de los indígenas en nuevos reductos de población creados por los misioneros. De allí que el descenso poblacional en los pueblos de misión en muchos casos fue consecuencia del abandono de los indígenas de sus pueblos originarios y su integración cultural en un nuevo ámbito cultural de desarraigo. ${ }^{28}$

Cuando el sistema misional colapsó después de la expulsión de los jesuitas en la década de 1760, los indígenas fueron desarraigados de sus comunidades y se convirtieron en el mayor componente étnico de la población regional. Pasaron a formar la base de los nuevos campesinos de raza mezclada llamados caboclo,s según la denominación portuguesa, o ribereño, en las áreas de dominación española. Esta población de caboclos o ribereños del siglo XIX era muy inferior numéricamente comparada con los informes que datan del siglo XVI, provenientes de estos mismos territorios.

El impacto en el ambiente de este sistema económico colonial fue paradójico: en tanto que las actividades extractivas provocaron un impacto negativo en los ecosistemas de las tierras bajas inundables y en los de las tierras altas, por su parte, el despoblamiento permitió que la selva se regenerara en áreas en donde había sido clareada durante los años tardíos del período precolombino, especialmente las sabanas en las tierras altas y las bajas planicies ribereñas. Fueron estas áreas las que precisamente visitaron los naturalistas científicos del siglo XIX, quienes erróneamente las catalogaron territorios virginales y prístinos. ${ }^{29}$

\section{Las nuevas plantaciones y el monocultivo}

Entretanto, los colonos europeos fueron introduciendo nuevas formas de utilización de la tierra con un impacto negativo, tales como plantaciones agrícolas, especialmente de cacao, azúcar y café, así como los ranchos ganaderos. La localización de estas nuevas explotaciones fue determinada por una combinación de factores ambientales y de geografía económica.

Los europeos notaron desde temprano que muchas partes de las tierras bajas contenían praderas y sabanas aptas para la ganadería vacuna y caballar. Para mediados del siglo XVIII, la mayor parte de las explotaciones

28 Vid. Langer y Jackson.

29 Vid. John Hemming, Naturalists in Paradise: Wallace, Bates and Spruce in the Amazon (London, Inglaterra: Thames and Hudson, 2015). 
a gran escala eran ranchos ganaderos: los ranchos de misioneros carmelitas y mercedarios en la isla de Marajó, en el estuario del Amazonas; los hatos ganaderos de los jesuitas en Llanos de Mojos; las estancias de colonos y de misioneros en los llanos venezolanos y las fazendas reales en el río Branco, en las sabanas que corren desde Roraima en el Amazonas portugués hasta el interior de Guyana.

Las plantaciones agrícolas durante el período colonial, con la importante excepción del cacao, se ubicaron principalmente cerca de la costa, casi exclusivamente en los suelos aluviales de las tierras bajas o en las partes bajas de la llamada tierra firme. El azúcar y el algodón en el Maranhao occidental y en las costas de las Guyanas estaban orientadas a la producción de exportación, pero en otros casos la agricultura era una extensión de la economía doméstica, que empleaba la caña de azúcar principalmente para la producción de aguardiente. Este producto era tan importante que la Corona nunca se atrevió a tasarlo con impuestos. No fue sino hasta la década de 1850, con el establecimiento de una navegación permanente con barcos de vapor, cuando se introdujeron los primeros ingenios azucareros movidos a vapor.

En el caso del cacao, el más importante producto de exportación del Amazonas antes del inicio de la explotación del caucho, su producción se mantuvo al margen del núcleo de plantaciones cercanas a la costa. Las plantaciones de cacao costeras fueron establecidas alrededor de Cayena y en los estuarios de Surinam durante el siglo XVIII, mediante el empleo de plantas silvestres de cacao traídas del interior durante las expediciones de extracción de productos de la selva. Sin embargo, el azúcar habría de resultar más rentable en estas regiones. De modo que, hacia mediados del siglo XVIII, la producción de cacao se había trasladado hacia el Amazonas portugués debido a una creciente escasez del cacao silvestre por su extracción excesiva. Esto motivó a los colonos portugueses a cultivarlo una vez que la Corona incentivó la actividad. El objetivo de desarrollar plantaciones de cacao constituye otra prueba del impacto de las actividades extractivistas en el "cacao silvestre", probablemente los restos de antiguas plantaciones de los indígenas del Amazonas del pre-contacto con los europeos. Estas siembras existían aún en los inicios del período colonial tanto a orillas del río Amazonas como de sus tributarios. ${ }^{30}$

Junto a la producción de cacao, la actividad ganadera también fue importante, especialmente a partir de mediados del siglo XIX, cuando se intensificó la producción de carne para abastecer los crecientes mercados urbanos. Su expansión se produjo principalmente en los más remotos llanos y sabanas

30 Cristina Adams, Rui Murrieta, Walter Neves, Mark Harris (eds.), Amazon Peasant Societies in a Changing Environment: Political Ecology, Invisibility and Modernity in the Rainforest (EE. UU.: Springer Science \& Business Media, 2008), 39. 
alejados de la vía principal del Amazonas. Los ranchos ganaderos provocaron un impacto ambiental mayor que el de las plantaciones de cacao, al impedir que la selva avanzara sobre las sabanas de origen precolonial.

Al comparar los patrones de subsistencia del período prehistórico tardío en la Gran Amazonía con los posteriores al arribo de los europeos, particularmente con los que la información etnográfica de los siglos XIX y $\mathrm{XX}$ suministra respecto de los pueblos indígenas en esas centurias, es posible observar un enorme cambio. En los últimos dos siglos predominó una agricultura de farináceos suplementada con pesca y caza, que ahora es considerada como una consecuencia de la dislocación de los complejos sistemas de organización sociopolítica prehistóricos y del despoblamiento de territorios densamente ocupados anteriormente. El cambio experimentado en la región amazónica provocó el retorno a sistemas de producción de alimentos menos intensivos, semejantes a los que existieron milenios atrás, en las etapas iniciales del desarrollo agrícola. El sistema agrícola de roza y quema, documentado por la etnografía del siglo XX, se asemeja más al modo de vida que existió en la Amazonía antes del desarrollo de las economías agrícolas de producción intensiva que surgieron durante el apogeo de los cacicazgos densamente poblados de los últimos siglos antes de la llegada de los europeos. ${ }^{31}$

\section{Conclusiones}

El repaso de los hallazgos de investigaciones recientes llevadas a cabo en la región de la Amazonía nos lleva a concluir que es errónea la idea, prevaleciente y aceptada incluso en medios académicos durante años, de que fueron las condiciones geográficas y ecológicas en esta inmensa región las que imposibilitaron el desarrollo de sociedades que superaran el nivel de simples economías de caza-recolección.

La aseveración de que los sistemas agrícolas indígenas de los territorios inter-fluviales de las tierras bajas tropicales eran rudimentarios y marginales debido a que se trataba en gran parte de zonas de tierras bajas tropicales, insuficientemente fértiles y, por tanto, no aptas para sustentar importantes núcleos poblacionales, resulta hoy insuficiente e inaceptable. También se ha logrado dilucidar la importancia que tuvieron los recursos alimenticios obtenidos por medio de la recolección, así como las proteínas obtenidas de insectos y nueces, y la enorme cantidad de plantas y animales semidomesticados.

A partir de la instalación de los europeos en el estuario del Amazonas comenzó un largo proceso de modificación del paisaje y de las sociedades que poblaban el extenso territorio amazónico. Se produjo un drástico

31 Curtenius Roosevelt,“The Rise and Fall...”, 270-271. 
descenso demográfico causado por la llegada de enfermedades aportadas por los europeos. Al principio, las mismas epidemias que asolaron las regiones nucleares de Mesoamérica y el Área Andina, y más tarde las enfermedades tropicales como el paludismo o malaria que se propagaron especialmente a partir del siglo XVII.

La drástica despoblación y el dominio impuesto por los europeos redujeron las antiguas sociedades a solo remanentes de lo que antes fueron. Las grandes y complejas sociedades organizadas en cacicazgos o estados prehistóricos se fragmentaron en pequeñas y dispersas aldeas. A su vez, la dispersión tuvo efectos significativos en la flora y la fauna, así como cambios socio-económicos profundos. Gracias a las recientes investigaciones etnohistóricas, arqueológicas, etnográficas y etnoecológicas se han podido trazar y documentar los cambios drásticos experimentados por las poblaciones indígenas durante la transición del período pre-contacto europeo al período de pos-contacto europeo. ${ }^{32}$

Considerar las sociedades actuales del Amazonas como un reflejo viviente de las otrora sociedades prehispánicas, o considerarlas como grupos que han logrado conservar su modo de vida al margen de la civilización occidental, tal y como este fue milenios atrás, es un error producto de la previa inexistencia de las avanzadas investigaciones que es posible realizar hoy en el campo de la arqueología y la etnografía.

32 Darrell Addison Posey, "Environmental and Social Implications of Pre and Postcontact Situations on Brazilian Indians: The Kayapó and a New Amazonian Synthesis", en: Curtenius Roosevelt, "The Rise and Fall...", 271. 